\title{
Analysis of Researches on Individuals with Special Needs and Their Academic Successes
}

\author{
Aytekin Hamdi BAŞKAN ${ }^{(\mathbb{D})}$, Ayşenur Oral ${ }^{(\mathbb{D})}$, Frrat DEMİROĞLU $^{3}{ }^{(\mathbb{D})}$ and Gözde KELEŞ ${ }^{4}$
}

${ }^{1}$ Giresun Üniversity, Department of coaching education, Giresun, Turkey

${ }^{2,3,4}$ Giresun Üniversity, Health Sciences Institute, Giresun, Turkey

*Corresponding author: aytekinbaskan@gmail.com

\begin{abstract}
The aim of this study is to examine the researches on the academic achievement of individuals with special needs in 20182019 and in the fields of science. It is reported that the number of the individuals with special needs in the world and Turkey is increasing day by day. It is known that there are difficulties in academic learning according to the type and level of special needs of people with special needs. The mainstreaming approach, which is accepted as the continuation of general education schools with their peers, provided that individuals with special needs receive special education services to support their education, has been widely adopted in many countries for the past thirty years. For the children who have special needs, inclusive education is really important to keep up with the society. The aim of co-education is to meet the social and emotional needs of students with special needs by integrating them academically and socially with their peers. In this study, the data archive of the Google trend search engine in 2018-2019 was used as a method for the comparative study of individuals with special needs and academic success, which are research topics. According to the research, it is found that the rate of research or people who have special needs is quite high compared to the academic success and it's observed when we consider all these issues between the cities people with special needs have been researched in nearly provinces of Turkey. Moreover, it is found that although the rates were quite high, the success wasn't and the number of searches are higher in Ankara and İstanbul than other provinces.
\end{abstract}

\section{Keywords}

Individuals with Special Requirement, Disabled, Academic Successes

\section{INTRODUCTION}

It is reported that the number of the individuals with special needs in the world and Turkey is increasing day by day (Cengiz et al., 2016). The special need is defined as the need for protection, care, rehabilitation, counseling and support services that have difficulties in adapting to social life and meeting daily needs, due to the loss of physical, mental, spiritual, sensory and social abilities of various degrees from birth or for any reason ( İnan et al., 2013).
The participation and acceptance of children in need of special education, like normal children, depends on their ability to perform many skills in daily life. The ability to fulfill these skills, to have a profession later in life and to live independently has a close relationship with the education given in pre-primary, other education levels and the quality of this education. It is wrong to expect the children with special needs in the classrooms of the schools that provide general education to normal 
developing children to learn the skills and procedures at the same level, and therefore to adapt the child with special needs to the schedule states that it will be against the basic principles of special education (Sinoplu, 2009).

Many studies have been conducted on the problems and ways they have in academic learning according to the type and level of special needs of people with special needs(Cengiz et al., 2016; Çevik, 2016; Okur \& Demir, 2019). Mental disability which is one of the developmental retardation, is the situation where the individual's mental functions and meaningful limitations and inadequacies are observed in the conceptual, social and practical adaptability skills (Fidan \& Akyol, 2011). Individuals with special needs can be educated and taught within themselves depending on the degree of exposure to the special need. Individuals with special needs can be trained and taught within themselves depending on the degree of exposure to the special need (Çevik, 2016). The mainstreaming approach, which is accepted as the fact that individuals with mild special needs benefit from special education services in addition to their academic education, with their peers in general education institutions, has been widely used for the last thirty years, as a result of this, in many countries, students with special needs are educated in general education schools together with their normally developing pers (Sucuoğlu \& Özokçu, 2005). Mainstreaming education is important for children with special needs to adapt to society. The aim of cooperative education is to provide the social and emotional needs of students with disabilities by integrating them academically and socially with their peers (Biçer \& Sarı, 2017).

There are different types of special needs students in learning environments. According to the types of special needs, learning difficulties related to the courses in the schedule in which the individual is studying are revealed. It is thought that $80-85 \%$ of the information obtained while learning is through vision ( Okur \& Demir, 2019). Learning is thought to be more effective since the use of materials and materials that support education activates more than one sense organ. These systems as called sense organs provide vision, hearing, touch, taste, and smell. In the lack of any of the sense organs, there may be deficiencies or inabilities in learning (Zorluoğlu \& Sözbilir, 2017).
It is an obvious fact that people with special needs have more difficulties in academic learning than their peers with normal development. Additional materials and sources should be provided according to the special needs type for each individual with special needs in teaching however, we know that the great majority of learning happens through vision therefore, it was observed that individuals with special needs of vision had more difficulty in academic learning compared to other special needs (Zorluoğlu \& Sözbilir, 2017; Okur \& Demir, 2019).

\section{MATERIALS AND METHODS}

In this study, a documentary research method based on data obtained from the web, archive, library and similar sources about the research problem has been applied. Search engines are software and websites that aim to give the fastest and most accurate results to the search queries made by users, where the sites on the internet are recorded and archived according to content such as articles, videos, files, images, etc. Google search engine is a mechanism used to search the content on the internet. The word trend means way, tendency and leaning. Based on the Turkish word of the trend, Google Trend (https://trends.Google.com/) can be described as a tool that shows Google or trends or search trends in other ways. In general, trends help measure the level of interest in search terms.

On the "Google trends" site, only the change of a group in relation to a variable over time can be explored, as well as a comparison of the trends of different groups in the same variable. The following variables are likely to be used to identify trends or trends. The following variables are likely to be used to identify trends or tendency.

\section{Geographical restriction}

It seems possible to limit the search worldwide and across countries. In this study, the worldwide and Turkey limitation was used.

\section{Time limitation}

There are time, day, month, year limitation options. In this study, 2018-2019 years were used in comparisons.

\section{Category limitation}

In this section, many categories are offered from shopping to science, finance to health and sports, with the option of all categories. In this study, only science option was used. 


\section{Search group limitation}

In this section, Google web search, image search, Google news search, Google shopping and Youtube search options are presented. In this study, Google scholar and Google trend method are applied.

\section{The values and numbers presented in trends}

Show interest in a relative search with the highest point in the graphic for a specific region and time. The value of 100 indicates the highest popularity of the period. Also, the value of 50 means half as popular. Similarly, a value of 0 is shown to be less than $1 \%$ of the top popularity of interest for a relative search.

\section{RESULTS}

The results of this study are presented in tables in a comparative way of the searches made at "https://trends.google.com".

Table 1. A comparison of the rate of special needs individuals and searched on the internet between 2018- 2019 academic term success in the science category in Turkey

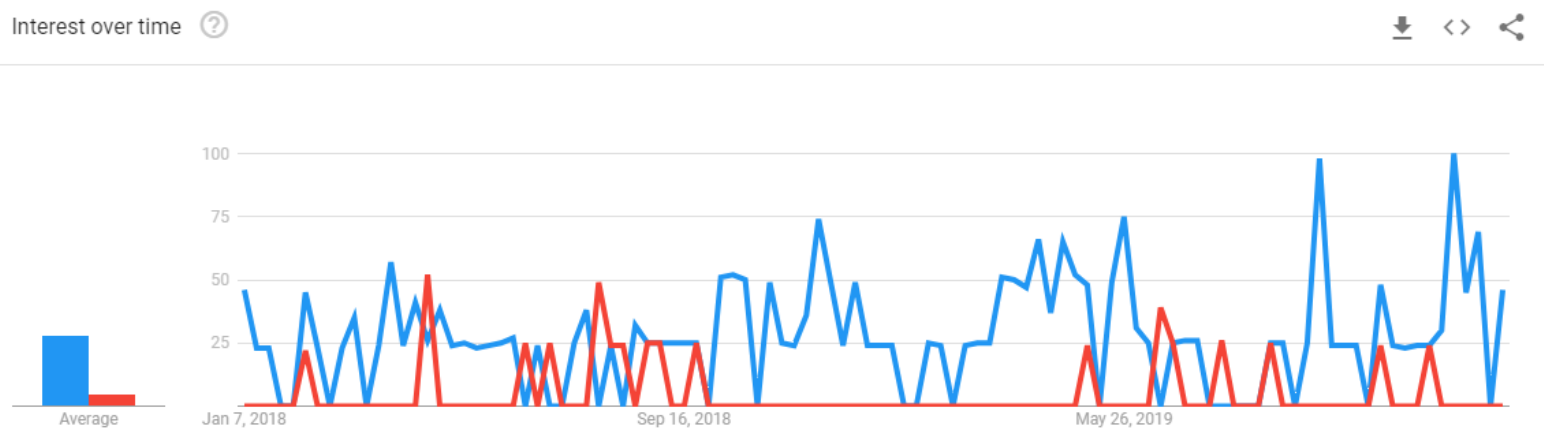

In Table 1, a line chart comparing the rates of search on the web in the science category between 2018 and 2019 of the terms of individual with special needs and academic success in Turkey was examined, and it was found that the rate of research of the tern of "individual with special needs" was generally higher than the rate of research of the term of "academic success".

Table 2. Comparison of inter-city internet search rates between 2018-2019 for individuals with special needs in the science category throughout Turkey

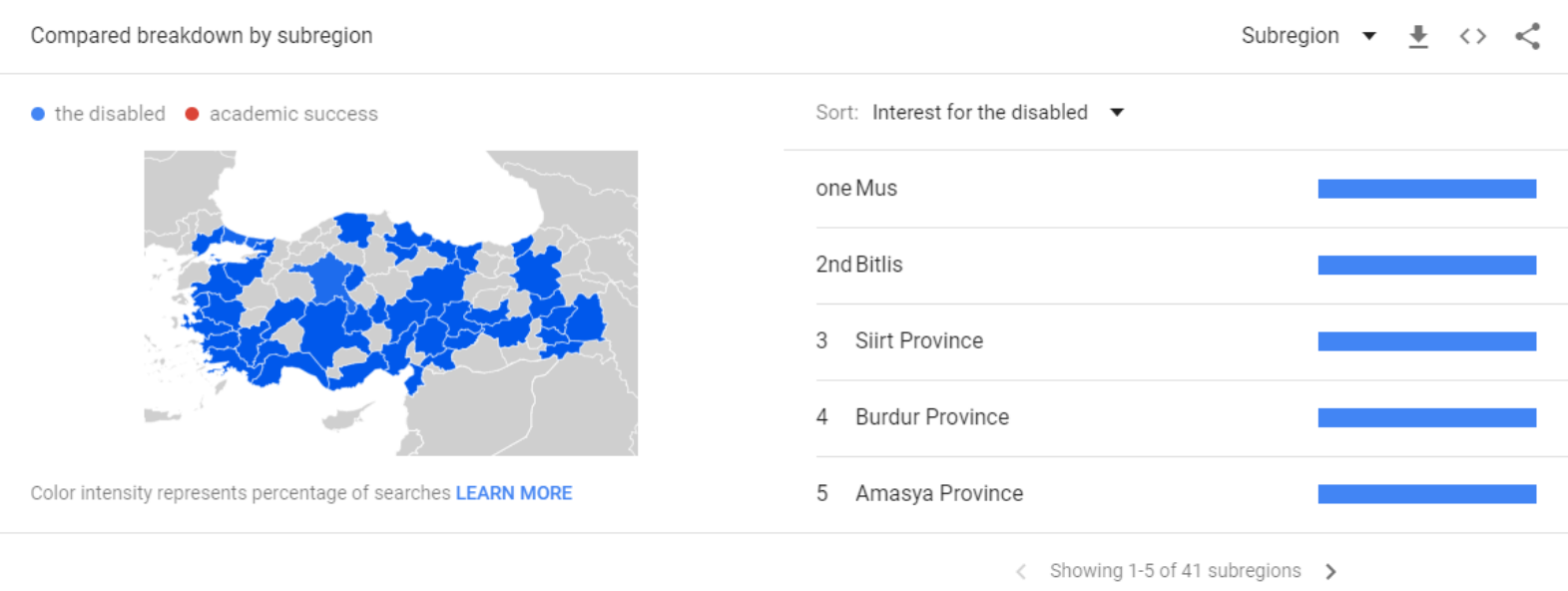

According to the data contained in Table 2, between 2018 and 2019 in Turkey, the search rate for the term of " individual with special needs" in the science category is $100 \%$ between the dates specified in 39 of the 41 sub-regions included in the scope of the study when comparing on a provincial basis. 
Table 3. The comparison between cities of the internet search rates between the years 2018-2019 in terms of academic achievement in the science category across Turkey

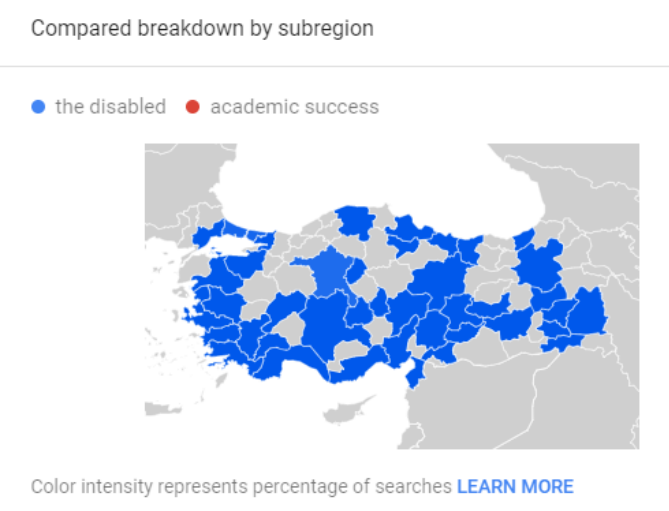

In Table 3, data comparing the provincialbased search rates of the term of "academic achievement" in the science category between 2018 and 2019 in Turkey are examined and 39 of

\section{DISCUSSION}

In this article, the subjects of "individuals with special needs" and "academic achievements of individuals with special needs" were investigated. In line with the data obtained as a result of the research, as explained in Table 1, it was observed that the rate of researching the term of "individuals with special needs" was higher than the term of "academic achievement of individuals with special needs". In Table 2, the rate of research of the term of a person with special needs is determined and explained by taking the criteria of 41 sub-regions (provinces) located in Turkey. The fact that this term has been researched in many provinces of Turkey in the search results suggests that information has been obtained to raise the living standards of individuals with special needs and it can be concluded that the increase in searches, not only in large cities, but also in many provinces from east to West, strengthens this assumption, helping to increase the awareness of individuals with special needs in society. According to the data obtained from Table 3, it was seen that the term of "academic achievement of individuals with special needs" was the subject of research in only 2 of the 41 sub-regions mentioned above and this situation, showing more sensitivity to the subjects such as socialization of individuals with special needs, their integration into the society and as a result of their daily life,

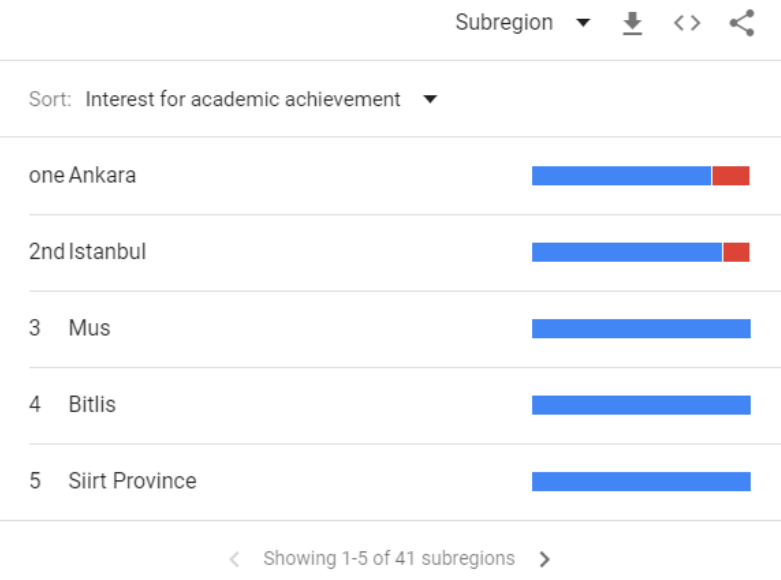

the 41 sub-regions included in the scope of the research do not have search data, while the remaining only 2 regions have a search rate of $16 \%$ in Ankara and 14\% in Istanbul.

makes us think that their academic success is not the same subject of research. Consideration of the future with this assumption, the study on improving the academic achievement of individuals with special needs are expected to only raise awareness in almost every province of Turkey in particular are not metropolitan. However, there is a point to consider that not every disability occurs as a result of the same type of inadequacy. While some types of disabilities are caused by physical disabilities, some types of disabilities are caused by mental disabilities. Therefore, the work to be done for each type of disability, the strategy to be followed and the method to be applied differ. There are many studies in the literature that support the study in this respect. For example, the information that graphic symbols are frequently used for teaching reading-writing is included in the literature, and it is emphasized that especially individuals with special education needs tend to define graphic symbols more easily than written words. (Koul et al., 2005) (Trudeau et al., 2007) In a different study, (Y1lmaz, 2009) stated that the physiotherapy method used in teaching writing to mentally disabled students in the first year of primary education has positive effects on children's writing skills. For the hearing impairment, which is a different type of disability, (Satılmış, 2010) stated that the active learning method is much more effective than the traditional teaching method on 
the achievement of the hearing impaired students in geography lesson. In (Tezcan, 2012) Tezcan's thesis in 2012, he asked students with mild intellectual disabilities to learn science and mathematics knowledge effectively, which can be useful in their daily lives and help them solve problems more easily, using information technologies and as a result, it increased the academic success of the students and the level of permanence in their learning. In another study whose type of disability was hearing, it was stated that the method of using graphic symbols in learning environments on individuals with disabilities and receiving positive feedback and this method enriched the classroom environment and had a facilitating effect in the learning process. (Karal et al., 2014) Based on the studies that support the subject in chronological order, it can be said that the correct studies and the variation of effective methods applied to increase the academic activities and success of individuals with special needs have increased over the years and the positive feedback obtained as a result of this can lead to new studies that can be made.

\section{REFERENCES}

Biçer, E., \& Sarı, O. T. (2017). Examınatıon of the relationship between theory of mind and executive function skills for students with normal development and students with mild mental disabilities. Journal of Theory and Practice in Education, 13(2), 261-276.

Cengiz, D. U., Yayan, E. H., Ercan, M. K., Kolcu, D., \& Akgül, F. (2016). Language acquisition and speech training in hearing impaired children. 1. international congress on woman and child health and training, (s. 1-6). Kocaeli.

Çevik, M. (2016). Effects of the project-based learning approaches on academic achievement and attitude of students studyıng at primary school with mild mental retardation in sciences course. Education Sciences (NWSAES), 11(1), 1-13.

Fidan, N. K., \& Akyol, H. (2011). The qualitative research on the improvements of the reading and comprehension skills of a student with mildly mental retardation. Theoretical Education Science Journal, 4(2), 16-29.

Karal, Y., Şılbır, L., Bahçekapılı, E., \& Atasoy, M. (2014). Learning materials created with graphic symbols for hearing impaired individuals. Journal of Instructional Technologies \& Teacher Education, 9-19.

Koul, R., Corwin, M., \& Hayes, S. (2005). Production of graphic symbol sentences by individuals with aphasia: efficacy of a computer-based augmentative and alternative communication intervention. Brain and Language, 92, 58-77.

İnan, S., Peker, G. C., Tekiner, S., Ak, F., \& Dağlı, Z. (2013). A Glance at Disability, the Situation of Disabled People and Provision of. TAF Preventive Medicine Bulletin, 12(6), 723-728.

Okur, M. R., \& Demir, M. (2019). The problems faced by visually impaired learners in their educational life determination, developing solutions for open and distance learning. Journal of Open Education Practices and Research AUAD, 5(2), 49-62.

Satılmış, E. (2010). Teachıng main earth shapes to hearing impaired students by using the actıve learning model. Master Thesis. Ankara, Altındağ: Gazi University, Institute of Education Sciences, Department of Secondary Education Social Fields Education. 5(11) 20-32.

Sinoplu, K. (2009). Mathemailcs teaching in mentally handicapped. selcuk university institute of science (Master Thesis), 1-75. Konya, Turkey.

Sucuoğlu, B., \& Özokçu, O. (2005). Social Skills of Inclusive Students. Ankara University Faculty of Educational Sciences Journal of Special Education, 6(1), 41-65.

Tezcan, C. (2012). Establishing a web-supported distance education system for children with mentally disabilities: Application of Mathematics and Science Lessons. Unpublished Master Thesis. Edirne: Trakya University, Institute of Science. 10-42.

Trudeau, N., Sutton, A., Dagenais, E., Broeck, S., \& Morford, J. (2007). Construction of graphic symbol utterances by children, teenagers, and adults: The effect of structure and task demands. Journal of Speech, Language, and Hearing Research, ProQuest Health and Medical Complete, 50, 5, 13141329.

Y1lmaz, S. (2009). Investigation of the effects of fine motor functions studied by using physiotherapy methods on writing skills in 
the first grade of primary education students with mental disabilities. Master Thesis. Konya, Turkey: Selcuk University, Institute of Social Sciences, Department of Special Education.

Zorluoğlu, S. L., \& Sözbilir, M. (2017). Learning Support Needs of Visually Impaired Students. Trakya University, Journal of Educational Sciences, 7(2), 659-682.

How to cite this article: Başkan, A.H., Oral, A., Demiroğlu, F. and Keleş, G. (2020). Analysis of Researches on Individuals with Special Needs and Their Academic Successes. Int J Disabil Sports Health Sci; 3(2):105-110. https:// doi.org/10.33438/ijdshs.764919. 